\title{
A theoretical study on 2-chloro-5-(2-hydroxyethyl)-4-methoxy-6-methylpyrimidine by DFT/ab initio calculations
}

\author{
HaCer PIR Gümüş, ÖMer TAMeR*, DAvut Avci, Yusuf Atalay
}

Sakarya University, Arts and Science Faculty, Department of Physics, 54187, Serdivan, Turkey

\begin{abstract}
Quantum chemical calculations have been performed to study the molecular geometry, ${ }^{1} \mathrm{H}$ and ${ }^{13} \mathrm{C}$ NMR chemical shifts, conformational, natural bond orbital (NBO) and nonlinear optical (NLO) properties of the 2-chloro-5-(2-hydroxyethyl)-4methoxy-6-methylpyrimidine molecule in the ground state using DFT and HF methods with $6-311++\mathrm{G}(\mathrm{d}, \mathrm{p})$ basis set. The optimized geometric parameters and ${ }^{1} \mathrm{H}$ and ${ }^{13} \mathrm{C}$ NMR chemical shifts have been compared with the experimental values of the title molecule. The results of the calculations show excellent agreement between the experimental and calculated frequencies at B3LYP/6-311++G(d,p) level. In order to provide a full understanding of the properties of the title molecule in the context of molecular orbital picture, the highest occupied molecular energy level ( $\left.\mathrm{E}_{\mathrm{HOMO}}\right)$, the lowest unoccupied molecular energy level $\left(\mathrm{E}_{\mathrm{LUMO}}\right)$, the energy difference $(\Delta \mathrm{E})$ between $\mathrm{E}_{\mathrm{HOMO}}$ and $\mathrm{E}_{\mathrm{LUMO}}$, electronegativity $(\chi)$, hardness $(\eta)$ and softness $(\mathrm{S})$ have been calculated using B3LYP/6-311++G(d,p) and HF/6-311++G(d,p) levels. The calculated HOMO and LUMO energies show that the charge transfer occurs within the title molecule.
\end{abstract}

Keywords: 2-chloro-5-(2-hydroxyethyl)-4-methoxy-6-methylpyrimidine, HF and DFT; NMR; NBO; NLO

(C) Wroclaw University of Technology.

\section{Introduction}

Pyrimidines are biologically important molecules that have heterocyclic nuclei valuable for the design of pharmaceutical agents [1]. The biological activities shown by 6-substituted uracil derivatives provide a new motivation to explore the chemical and biological activities of these pyrimidine derivatives [2-8]. Uracil derivatives as well as their nucleosides which have significant status in the field of chemotherapy, are substituted either at C5 or C6 positions. Especially, 5-substituted uracil analogs have been extensively investigated to use in cancer [9, 10] and viral chemotherapy [11, 12], as enzyme inhibitors [13-16] and in the synthesis of modified nucleotides [17, 18]. Lately, it has been realized that some $\mathrm{C} 5$ and/or C6 substituted pyrimidine derivatives exhibit antiviral and cytostatic activities [1].

\footnotetext{
*E-mail: omertamer@ sakarya.edu.tr
}

The novel type of nonconventional C-6 (2chloro-5-(2-hydroxyethyl)-4-methoxy-6-methylpyrimidine molecule) pyrimidine nucleoside mimetics as model molecules for the development of tracer molecules in positron-emission tomography (PET) were synthesized [1]. Recently, 2-chloro-5-(2-hydroxyethyl)-4-methoxy6-methylpyrimidine $\left[\mathrm{C}_{8} \mathrm{H}_{11} \mathrm{ClN}_{2} \mathrm{O}_{2}\right]$ was synthesized and characterized using $\mathrm{X}$-ray diffraction method and its structure was elucidated with ${ }^{1} \mathrm{H}$ and ${ }^{13} \mathrm{C}$ spectra by Kraljevic et al. [1]. However, to the best of our knowledge, the theoretical calculations of conformational, natural bond orbital (NBO) and nonlinear optical (NLO) analysis, molecular geometry, molecular frontier orbital energy and electronic properties of the title molecule have been not investigated yet.

The aim of the present work is to provide a full description and understanding of structural, spectroscopic, electric and electronic properties of the title molecule. In this regard, DFT and HF methods have been used to calculate the ground state 
molecular structure [19], bonding features, conformational study [20], natural bond orbital (NBO) [21] and nonlinear optical (NLO) [22] analysis, ${ }^{1} \mathrm{H}$ and ${ }^{13} \mathrm{C}$ NMR chemical shifts [23], molecular frontier orbital energies [24-26], Mulliken and NBO charges as well as the molecular electrostatic potential (MEP) map [27] for the title molecule.

\section{Computational details}

In the ground state, the molecular structure of the title molecule was calculated by performing both the Hartree-Fock (HF) and the density functional theory (DFT) by a hydrid functional B3LYP functional (Becke's three parameter hybrid functional using the LYP correlation functional) methods $[28,29]$ at $6-311++\mathrm{G}(\mathrm{d}, \mathrm{p})$ level. Based on the optimized geometry, ${ }^{1} \mathrm{H}$ and ${ }^{13} \mathrm{C}$ NMR chemical shifts were calculated within the gauge-independent atomic orbital (GIAO), individual gages for atoms in molecules (IGAIM) and continuous set of gauge transformations (CSGT) methods applying B3LYP and HF methods. The conformational and natural bond orbital (NBO) analyses, frontier molecular orbitals, atomic charges and molecular electrostatic potential surface calculations were performed using Gaussian 09W program package [30] and GaussView 5 molecular visualization program [31]. DFT and HF methods were also used in the calculations of dipole moments, polarizability and hyperpolarizability values of the title molecule.

\section{Results and discussion}

\subsection{Geometric optimization and confor- mational analysis}

The 2-chloro-5-(2-hydroxyethyl)-4-methoxy-6methylpyrimidine $\left[\mathrm{C}_{8} \mathrm{H}_{11} \mathrm{ClN}_{2} \mathrm{O}_{2}\right]$ molecule in triclinic system with a noncentrosymmetric space group $\mathrm{P} 1$, and unit cell parameters $\mathrm{a}=7.5752(2) \AA$, $\mathrm{b}=7.9618(2) \AA, \quad \mathrm{c}=7.9984(2) \AA, \alpha=$ $82.878(2)^{\circ}, \beta=79.812(2)^{\circ}, \gamma=81.739(2)^{\circ}$ and $\mathrm{V}=467.46(2) \AA^{3}$ has been synthesized by Kraljevic et al. [1]. The experimental molecular structure with the numbering of atoms and the optimized structure obtained at B3LYP/6$311++\mathrm{G}(\mathrm{d}, \mathrm{p})$ are shown in Fig. 1a [1] and Fig. 1b, respectively. The crystal structure of the title molecule was taken from Cambridge Crystallographic Data Center (CCDC 749762). The geometric parameters (bond lengths, bond angles and dihedral angles) calculated using HF and DFT/B3LYP methods at $6-311++\mathrm{G}(\mathrm{d}, \mathrm{p})$ level for the title molecule were compared with the experimental parameters [1] in Table 1.

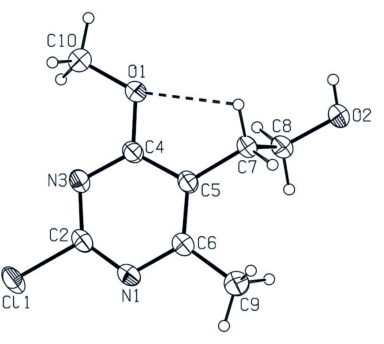

(a)

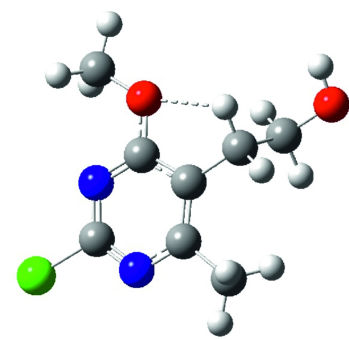

(b)
Fig. 1. Experimental (a) and optimized geometric structure of the title molecule obtained at B3LYP/6$311++\mathrm{G}(\mathrm{d}, \mathrm{p})$ level (b).

The O1-C4 bond length was determined to be $1.333 \AA$ [1] and this bond length, calculated using HF and B3LYP methods with 6-311++G(d,p) basis set, was determined as $1.318 \AA$ and $1.342 \AA$, respectively. The experimental N1-C2 bond length of $1.306 \AA[1]$ was calculated as $1.292 \AA$ and $1.312 \AA$, respectively. The $\mathrm{C} 5-\mathrm{C} 6$ bond length defined as $1.376 \AA$ [1] was calculated as $1.380 \AA$ and $1.395 \AA$ using HF and B3LYP methods. The C11-C2 bond length defined as $1.739 \AA$ [1] was calculated as $1.736 \AA$ and $1.758 \AA$, respectively. The C2-N1C6 bond angle was found as $115.21^{\circ}$ [1], and this bond angle calculated using HF and B3LYP methods was found to be $116.44^{\circ}$ and $116.26^{\circ}$. The N1C2-C11 experimental bond angle of $115.24^{\circ}$ [1] was calculated to be $116.54^{\circ}$ and $116.33^{\circ}$, respectively. We can note that the results obtained in this study, which belong to the solid phase and theoretical calculations, can be classified as favorable, as they are supported by the experimental data. The largest differences between experimental and theoretical bond length and experimental and 
Table 1. Experimental [1] and calculated bond lengths, bond angles and dihedral angles for the title molecule.

\begin{tabular}{|c|c|c|c|}
\hline & \multirow{2}{*}{$\begin{array}{c}\text { Exp. [1] } \\
\text { X-ray }\end{array}$} & \multicolumn{2}{|c|}{ Theoretical calculations } \\
\hline & & $\mathrm{HF} / 6-311++\mathrm{G}(\mathrm{d}, \mathrm{p})$ & B3LYP/6-311++G(d,p) \\
\hline \multicolumn{4}{|l|}{ Bond length $(\AA)$} \\
\hline $\mathrm{N}_{1}-\mathrm{C}_{2}$ & 1.306 & 1.292 & 1.312 \\
\hline $\mathrm{N}_{1}-\mathrm{C}_{6}$ & 1.362 & 1.342 & 1.353 \\
\hline $\mathrm{N}_{3}-\mathrm{C}_{2}$ & 1.317 & 1.312 & 1.325 \\
\hline $\mathrm{N}_{3}-\mathrm{C}_{4}$ & 1.328 & 1.311 & 1.328 \\
\hline $\mathrm{C}_{4}-\mathrm{C}_{5}$ & 1.408 & 1.404 & 1.410 \\
\hline $\mathrm{C}_{5}-\mathrm{C}_{6}$ & 1.376 & 1.380 & 1.395 \\
\hline $\mathrm{C}_{5}-\mathrm{C}_{7}$ & 1.502 & 1.511 & 1.508 \\
\hline $\mathrm{C}_{6}-\mathrm{C}_{9}$ & 1.502 & 1.506 & 1.505 \\
\hline $\mathrm{C}_{7}-\mathrm{C}_{8}$ & 1.519 & 1.530 & 1.539 \\
\hline $\mathrm{Cl}_{1}-\mathrm{C}_{2}$ & 1.739 & 1.736 & 1.758 \\
\hline $\mathrm{O}_{1}-\mathrm{C}_{4}$ & 1.333 & 1.318 & 1.342 \\
\hline $\mathrm{O}_{1}-\mathrm{C}_{10}$ & 1.435 & 1.418 & 1.440 \\
\hline $\mathrm{O}_{2}-\mathrm{C}_{8}$ & 1.414 & 1.402 & 1.425 \\
\hline \multicolumn{4}{|l|}{ Bond angles $\left({ }^{\circ}\right)$} \\
\hline $\mathrm{C}_{2}-\mathrm{N}_{1}-\mathrm{C}_{6}$ & 115.21 & 116.44 & 116.26 \\
\hline $\mathrm{C}_{2}-\mathrm{N}_{3}-\mathrm{C}_{4}$ & 114.20 & 115.52 & 115.23 \\
\hline $\mathrm{N}_{1}-\mathrm{C}_{2}-\mathrm{N}_{3}$ & 129.56 & 128.03 & 128.21 \\
\hline $\mathrm{N}_{1}-\mathrm{C}_{6}-\mathrm{C}_{9}$ & 115.18 & 115.22 & 115.65 \\
\hline $\mathrm{C}_{5}-\mathrm{C}_{7}-\mathrm{C}_{8}$ & 111.87 & 112.88 & 112.74 \\
\hline $\mathrm{C}_{4}-\mathrm{O}_{1}-\mathrm{C}_{10}$ & 117.56 & 119.47 & 117.92 \\
\hline $\mathrm{N}_{1}-\mathrm{C}_{2}-\mathrm{Cl}_{1}$ & 115.24 & 116.54 & 116.33 \\
\hline $\mathrm{N}_{3}-\mathrm{C}_{2}-\mathrm{Cl}_{1}$ & 115.20 & 115.43 & 115.46 \\
\hline $\mathrm{N}_{3}-\mathrm{C}_{4}-\mathrm{O}_{1}$ & 119.40 & 118.90 & 118.95 \\
\hline $\mathrm{O}_{1}-\mathrm{C}_{4}-\mathrm{C}_{5}$ & 116.85 & 117.68 & 117.58 \\
\hline $\mathrm{O}_{2}-\mathrm{C}_{8}-\mathrm{C}_{7}$ & 112.10 & 111.93 & 112.24 \\
\hline \multicolumn{4}{|l|}{ Dihedral angles $\left({ }^{\circ}\right)$} \\
\hline $\mathrm{C}_{6}-\mathrm{N}_{1}-\mathrm{C}_{2}-\mathrm{N}_{3}$ & -0.70 & 0.18 & 0.13 \\
\hline $\mathrm{C}_{4}-\mathrm{N}_{3}-\mathrm{C}_{2}-\mathrm{N}_{1}$ & 0.90 & -0.12 & -0.00 \\
\hline $\mathrm{C}_{2}-\mathrm{N}_{1}-\mathrm{C}_{6}-\mathrm{C}_{5}$ & -0.12 & 0.12 & 0.10 \\
\hline $\mathrm{C}_{6}-\mathrm{N}_{1}-\mathrm{C}_{2}-\mathrm{Cl}_{1}$ & 179.02 & -179.90 & -179.93 \\
\hline $\mathrm{C}_{4}-\mathrm{N}_{3}-\mathrm{C}_{2}-\mathrm{Cl}_{1}$ & -178.80 & 179.96 & -179.94 \\
\hline $\mathrm{C}_{2}-\mathrm{N}_{3}-\mathrm{C}_{4}-\mathrm{O}_{1}$ & 179.49 & 179.91 & 179.94 \\
\hline $\mathrm{O}_{1}-\mathrm{C}_{4}-\mathrm{C}_{5}-\mathrm{C}_{7}$ & -1.96 & 0.16 & -0.59 \\
\hline $\mathrm{C}_{5}-\mathrm{C}_{7}-\mathrm{C}_{8}-\mathrm{O}_{2}$ & -177.66 & -178.87 & -178.22 \\
\hline
\end{tabular}

theoretical bond angle are about $0.017 \AA$ and about $2.09^{\circ}$, respectively. As can be seen, there is a good agreement between the experimental and calculated geometric parameters.
To make comparison with experimental results, we have presented linear correlation coefficients $\left(\mathrm{R}^{2}\right)$ for linear regression analysis of theoretical and experimental geometrical parameters 
(Fig. 2). $\mathrm{R}^{2}$ values for bond lengths are found to be 0.9965 and 0.9946 , while those for bond angles are found to be 0.9911 and 0.9732 using B3LYP, DFT/B3LYP and HF methods, respectively. As one can easily see from the above cited correlation coefficients, they are similar to each other for two levels of geometric optimization of the title molecule. The best correlation coefficient was obtained for DFT/B3LYP method with 6$311++\mathrm{G}(\mathrm{d}, \mathrm{p})$ basis set. Minor differences derived from the experimental results are observed for the solid phase, while the theoretical calculations were performed in the gas phase.
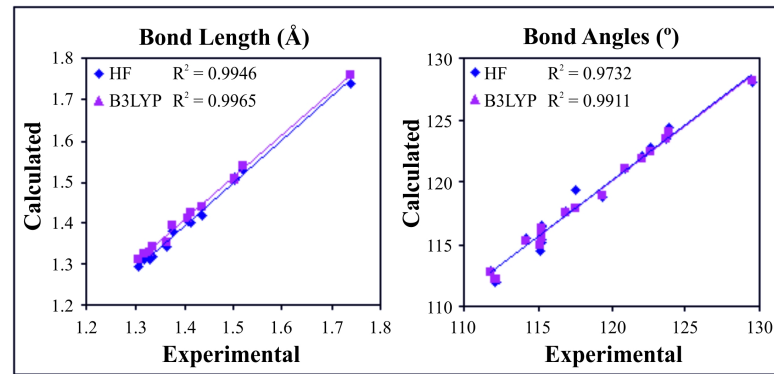

Fig. 2. Correlation graphs of experimental and calculated molecular bond lengths and bond angles of the title molecule.

The conformational analysis has been performed to determine the most stable conformers of the title molecules using the DFT/6-31G computational level. From the rotation of different groups, the minimum energy conformations are obtained, and valuable structural information about the protein can be acquired. In order to reveal all possible conformations of the title molecule, a detailed potential energy curve for $\tau(\mathrm{C} 6-\mathrm{C} 5-\mathrm{C} 7-\mathrm{C} 8)$ dihedral angle has been determined in steps of $10^{\circ}$ (Fig. 3). The structure of the highest and the lowest energy conformers for $\tau(\mathrm{C} 6-\mathrm{C} 5-\mathrm{C} 7-\mathrm{C} 8)$ dihedral angle and the computed values of these dihedral angles are given in Fig. 4. For this maximum energy curve for $\tau(\mathrm{C} 6-\mathrm{C} 5-\mathrm{C} 7-\mathrm{C} 8)$, dihedral angles have been obtained as $185.674^{\circ}$ and $355.674^{\circ}$ as shown in Fig. 3. The maximum energy obtained at $185.674^{\circ}$ is -1031.4062 Hartree and $355.674^{\circ}$ is -1031.4029 Hartree. The global minimum energy obtained at $255.674^{\circ}$ is -1031.4108 Hartree. Conformers resulting from unconstrained optimizations of the highest and the lowest energy structures calculated using B3LYP/6-31G are shown in Fig. 4. Additionally, 3D potential energy surface (PES) scan simulated for the dihedral angles of C6-C5-C7-C8 and C5-C4-O1-C10 is given in Fig. 5.

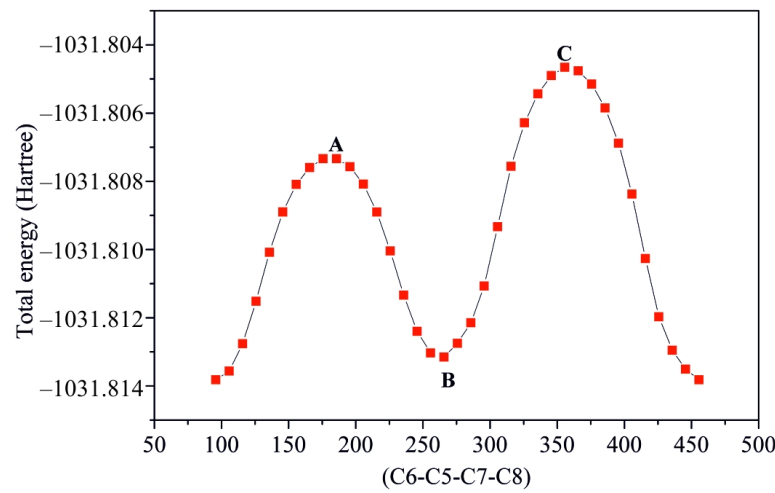

Fig. 3. One-dimensional potential energy surface (PES) scan of the title molecule using DFT/6-31G level.

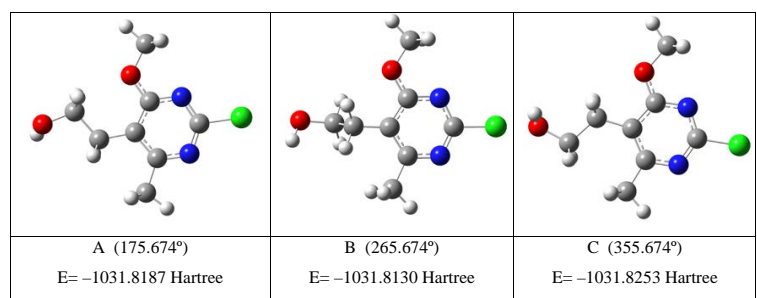

Fig. 4. Highest and lowest energy conformations of the title molecule using B3LYP/6-31G level.

\subsection{NMR spectra analysis}

A comparison of experimental and theoretical spectra can be very useful to make correct designation of peaks and understand the basic chemical shift molecular structure relationship. In this study, ${ }^{1} \mathrm{H}$ and ${ }^{13} \mathrm{C}$ NMR chemical shifts have been calculated within the gauge-independent atomic orbital (GIAO) [32-34], individual gages for atoms in molecules (IGAIM) [35] and continuous set of gauge transformations (CSGT) [36] methods applying B3LYP and HF methods with 6-311++G(d,p) basis set (Table 2). Correlation graphs of calculated and experimental ${ }^{1} \mathrm{H}$ NMR 


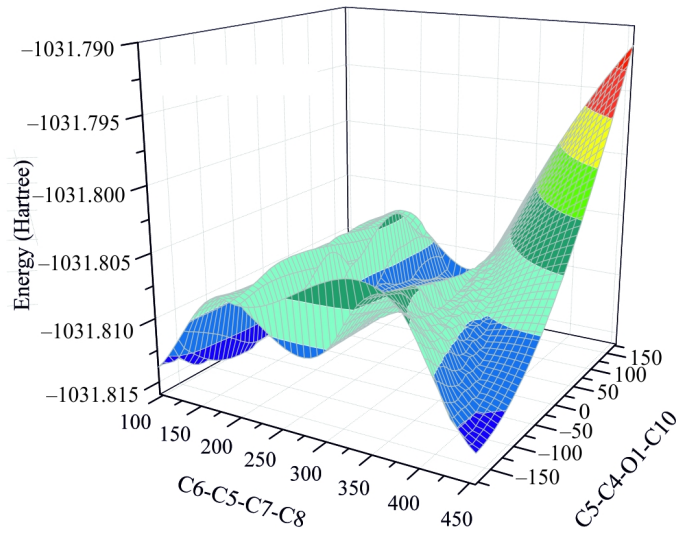

Fig. 5. Simulated 3D potential energy surface (PES) scan obtained at B3LYP/6-31G level. Simulated 3D potential energy surface (PES) scan obtained at B3LYP/6-31G level.

and ${ }^{13} \mathrm{C}$ NMR chemical shifts for the title molecule are presented in Fig. 6.
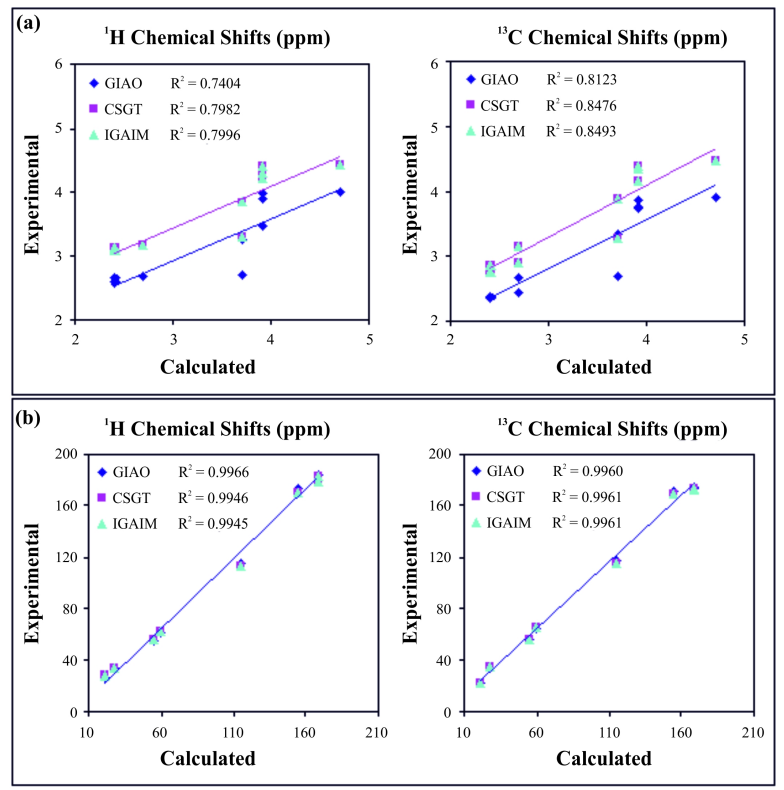

Fig. 6. Correlation graphs between the experimental and calculated ${ }^{1} \mathrm{H}$ and ${ }^{13} \mathrm{C}$ chemical shifts of the title molecule using $\mathrm{HF} / 6-311++\mathrm{G}(\mathrm{d}, \mathrm{p})$ level (a) B3LYP/6-311++G(d,p) level (b).

It is well known that aromatic carbons give signals in the range of 100 to $150 \mathrm{ppm}$. However, it has been found that calculated $\mathrm{C} 2, \mathrm{C} 4$ and C6 ${ }^{13} \mathrm{C}$ NMR peaks are higher than $150 \mathrm{ppm}$. It is well known that the electronegative atom reduces the electron density of carbon atom, so its ${ }^{13} \mathrm{C}$ NMR peak shifts to downfield region in the NMR spectrum. Such effects of chemical shifts [37] are very well known in the literature [38]. The carbon atoms $\mathrm{C} 2, \mathrm{C} 4$ and $\mathrm{C} 6$ were calculated in the down field due to the deshielding effect of $\mathrm{N}$ and $\mathrm{Cl}$ atoms. From Fig. 6, correlation coefficients for DFT/B3LYP method are found in the range of 0.9960 and 0.9961 , while those for HF method are found in the range of 0.8123 and 0.8493 for ${ }^{13} \mathrm{C}$ NMR peaks. Consequently, it is demonstrated that DFT/B3LYP level gives more consistent results than HF method.

The ${ }^{1} \mathrm{H}$ chemical shift value for $\mathrm{H} 2$ atom was found to be $4.71 \mathrm{ppm}$ [1], and this chemical shift was calculated in the range of 3.912 and $4.475 \mathrm{ppm}$. The NMR peak, which is responsible for $\mathrm{H} 2$ atom, shifts to downfield region due to the electronegative $\mathrm{O}$ atom. The title molecule has two methyl groups, and these groups give NMR peaks at different regions. The methyl group attached to $\mathrm{O}$ atom gives peaks in the range of 3.866 to $3.739 \mathrm{ppm}$, while those attached to $\mathrm{C}$ atom give peaks in the range of 2.390 to $2.361 \mathrm{ppm}$ at B3LYP level. The reason of the increasing ${ }^{1} \mathrm{H}$ NMR peaks of the methyl group attached to $\mathrm{O}$ atom is due to the electronegativity of $\mathrm{O}$ atom. If we make a comparison between the ${ }^{13} \mathrm{C}$ NMR calculation methods, it can be said that IGAIM method gives results closer to the experimental ones than GIAO and CSGT methods. From Fig. 6, it can be seen that GIAO gives the best results for ${ }^{1} \mathrm{H}$ NMR calculation at DFT/B3LYP level.

\subsection{Natural Bonding Orbital (NBO) analysis}

Natural bonding orbital (NBO) analysis provides an efficient tool for studying intra- and inter-molecular bonding and interaction among bonds, and also provides a convenient basis for investigating charge transfer or conjugative interactions in molecular systems [39]. NBO calculations have been performed using DFT and HF methods in order to understand various second-order interactions between the filled orbitals of one subsystem 
Table 2. The calculated (with 6-311++G(d,p) basis set) and experimental ${ }^{13} \mathrm{C}$ and ${ }^{1} \mathrm{H}$ isotropic NMR chemical shifts (with respect to TMS, all values in ppm) for the title molecule.

\begin{tabular}{lccccccc}
\hline & Exp. [1] & \multicolumn{7}{c}{ Theoretical } \\
& & \multicolumn{2}{c}{ GIAO Method } & \multicolumn{2}{c}{ CSGT Method } & \multicolumn{2}{c}{ IGAIM Method } \\
& & HF & B3LYP & HF & B3LYP & HF & B3LYP \\
\hline \hline${ }^{1} \mathrm{H}$ & & & & & & & \\
\hline $\mathrm{H}_{2}$ & 4.71 & 4.005 & 3.912 & 4.430 & 4.469 & 4.430 & 4.475 \\
$\mathrm{H}_{10 A}$ & 3.92 & 3.980 & 3.866 & 4.407 & 4.382 & 4.407 & 4.382 \\
$\mathrm{H}_{10 B}$ & 3.92 & 3.889 & 3.758 & 4.304 & 4.349 & 4.303 & 4.349 \\
$\mathrm{H}_{10 C}$ & 3.92 & 3.470 & 3.739 & 4.203 & 4.157 & 4.210 & 4.156 \\
$\mathrm{H}_{8 A}$ & 3.71 & 3.246 & 3.338 & 3.833 & 3.881 & 3.839 & 3.887 \\
$\mathrm{H}_{8 B}$ & 3.71 & 2.687 & 2.683 & 3.288 & 3.263 & 3.294 & 3.269 \\
$\mathrm{H}_{7 A}$ & 2.69 & 2.659 & 2.656 & 3.155 & 3.147 & 3.161 & 3.152 \\
$\mathrm{H}_{7 B}$ & 2.69 & 2.657 & 2.434 & 3.149 & 2.893 & 3.151 & 2.894 \\
$\mathrm{H}_{9 A}$ & 2.41 & 2.638 & 2.390 & 3.108 & 2.848 & 3.111 & 2.851 \\
$\mathrm{H}_{9 B}$ & 2.41 & 2.573 & 2.361 & 3.065 & 2.733 & 3.066 & 2.734 \\
\hline${ }_{13} \mathrm{C}$ & & & & & & & \\
\hline $\mathrm{C}_{4}$ & 168.66 & 183.98 & 174.46 & 182.69 & 173.19 & 182.69 & 173.20 \\
$\mathrm{C}_{6}$ & 168.05 & 179.93 & 173.54 & 178.63 & 172.21 & 178.63 & 172.21 \\
$\mathrm{C}_{2}$ & 155.33 & 173.17 & 171.34 & 170.41 & 168.83 & 170.43 & 168.84 \\
$\mathrm{C}_{5}$ & 115.64 & 115.25 & 117.71 & 113.51 & 115.68 & 113.51 & 115.68 \\
$\mathrm{C}_{8}$ & 59.03 & 61.003 & 64.639 & 62.146 & 65.464 & 62.141 & 65.455 \\
$\mathrm{C}_{10}$ & 54.74 & 54.936 & 55.391 & 55.883 & 55.608 & 55.864 & 55.586 \\
$\mathrm{C}_{7}$ & 28.26 & 32.757 & 33.639 & 33.510 & 34.149 & 33.502 & 34.138 \\
$\mathrm{C}_{9}$ & 21.18 & 27.188 & 22.734 & 27.749 & 22.941 & 27.731 & 22.920 \\
\hline & & & & & & &
\end{tabular}

and vacant orbitals of another subsystem, which are a measure of the intermolecular delocalization or hyperconjugation. NBO method makes possible to examine hyperconjugative interactions due to electron transfers from filled bonding orbitals (donor) to empty anti-bonding orbitals (acceptor) [39, 40]. In the title molecule the examined hyperconjugative interactions are of second-order type and take place between $\sigma$ and $\sigma^{*}$ orbitals or between electron lone-pairs (Lp) and $\sigma^{*}$ orbitals.

The second-order Fock matrix was used to evaluate the donor-acceptor interactions in the NBO basis [41]. The interactions result in a loss of occupancy from the localized NBO of the idealized Lewis structure into an empty non-Lewis orbital. For each donor (i) and acceptor (j), the stabilization energy $\mathrm{E}(2)$ associated with the delocalization $\mathrm{i} \rightarrow \mathrm{j}$ is estimated as [42]:

$$
E(2)=\Delta E_{i j}=q_{i} \frac{F(i, j)^{2}}{\varepsilon_{j}-\varepsilon_{i}^{\prime}}
$$

where $\mathrm{q}_{\mathrm{i}}$ is donor orbital occupancy, $\varepsilon_{\mathrm{i}}$ and $\varepsilon_{j}$ are diagonal elements and $F(i, j)$ is the off-diagonal NBO Fock matrix element. In NBO analysis, large $\mathrm{E}(2)$ values imply an intensive interaction between electron-donors and electron-acceptors and the greater the extent of conjugation of the whole system, the more possible intensive interactions. The hyperconjugative $\sigma \rightarrow \sigma^{*}$ interactions play a highly important role. These interactions represent the weak departures from a strictly localized natural Lewis structure that constitutes the primary "noncovalent" effects. The results of NBO analysis tabulated in Table 3 indicate that there is a strong 
hyperconjugative interaction $\pi\left(\mathrm{N}_{1}-\mathrm{C}_{2}\right) \rightarrow \pi^{*}$ $\left(\mathrm{C}_{5}-\mathrm{C}_{6}\right)$ and $\pi\left(\mathrm{N}_{3}-\mathrm{C}_{4}\right) \rightarrow \pi^{*}\left(\mathrm{~N}_{1}-\mathrm{C}_{2}\right)$ for the title molecule and their interaction energies are found as 53.52 and $77.62 \mathrm{kcal} / \mathrm{mol}$ for HF method, respectively. The second-order perturbation theory analysis of Fock matrix in NBO basis shows strong intramolecular hyperconjugative interactions of electrons. The energy contributions of LP3 $\left(\mathrm{Cl}_{1}\right) \rightarrow \pi^{*}\left(\mathrm{~N}_{1}-\mathrm{C}_{2}\right), \mathrm{LP} 1\left(\mathrm{~N}_{1}\right) \rightarrow \sigma^{*}\left(\mathrm{~N}_{3}-\mathrm{C}_{2}\right)$ and $\mathrm{LP} 2\left(\mathrm{O}_{1}\right) \rightarrow \sigma^{*}\left(\mathrm{~N}_{3}-\mathrm{C}_{4}\right)$ interactions were calculated as 24.36, 17.38 and $58.43 \mathrm{kcal} / \mathrm{mol}$ for $\mathrm{HF}$ method. So, there is a possibility for delocalization of a lone pair (LP) of electrons. The electron density of conjugated bond of aromatic ring $(\sim 1.99 \mathrm{e})$ clearly demonstrates strong delocalization for the title molecule.

\subsection{Electronic properties}

The highest occupied molecular orbital (HOMO) and the lowest unoccupied molecular orbital (LUMO) energies are very important parameters for quantum chemistry. HOMO and LUMO are the main orbitals taking part in chemical reactions. HOMO energy characterizes the ability of electron giving, while LUMO energy characterizes the ability of electron accepting. Energy gap between HOMO and LUMO characterizes the molecular chemical stability and it is a critical parameter in determining molecular charge transport properties because it is a measure of electron conductivity [43].

The total energy, HOMO and LUMO energies, the energy gap $(\Delta \mathrm{E})$, ionization potential (I), electron affinity (A), absolute electronegativity $(\chi)$, absolute hardness $(\eta)$ and softness (S) for 2-chloro-5-(2-hydroxyethyl)-4-methoxy-6methylpyrimidine molecule have been calculated at HF and DFT(B3LYP) level in the $6-311++\mathrm{G}(\mathrm{d}, \mathrm{p})$ basis set, and obtained results for these parameters are given in Table 4. The calculated HOMO and LUMO energies show that charge transfer occurs within the title molecule. HOMO and LUMO energies were calculated as -9.6052 and $0.9178 \mathrm{eV}$ for $\mathrm{HF}$ level and -7.1036 and $-1.3464 \mathrm{eV}$ for B3LYP level, respectively. The energy gap between the HOMO and LUMO orbital was predicted as
10.5230 and $5.7572 \mathrm{eV}$ for HF and B3LYP level in the $6-311++\mathrm{G}(\mathrm{d}, \mathrm{p})$ basis set, respectively.

Using HOMO and LUMO energy values, electronegativity and chemical hardness of a molecule can be calculated as follows: $\chi=\frac{\mathrm{I}+\mathrm{A}}{2}$ (electronegativity), $\eta=\frac{I-A}{2}$ (chemical hardness) $S=\frac{1}{2 \eta}$ (chemical softness) where I and A are ionization potential and electron affinity, and $\mathrm{I}=-\mathrm{E}_{\mathrm{HOMO}}$ and $\mathrm{A}=-\mathrm{E}_{\mathrm{LUMO}}$, respectively [44]. While $\chi$ values were calculated as $4.3437 \mathrm{eV}$ and $4.2250 \mathrm{eV}$, $\eta$ values were calculated as $5.2615 \mathrm{eV}$ and $2.8786 \mathrm{eV}$ for HF and B3LYP levels, respectively. In general, for any two molecules, electron is partially transferred from one of low $\chi$ to that of high $\chi$, (that is, electrons flow from high chemical potential to low chemical potential).

Surfaces for the frontier molecular orbitals (FMOs) were drawn to understand the bonding scheme of present molecule (Fig. 7). The coefficients of Frontier $\alpha$-spin molecular orbitals for title molecule using B3LYP/6-31++G(d,p) level have been calculated as follows:

\begin{tabular}{|c|c|c|c|}
\hline & $-0.01 \cdot 3 \mathrm{Pz}^{\mathrm{N} 1}$ & $2 \mathrm{Pz}^{\mathrm{N} 3}$ & \\
\hline $10 \cdot 3 \mathrm{Pz}^{\mathrm{N} 3}$ & $+0.06 \cdot 2 \mathrm{Pz}^{\mathrm{O} 1}$ & $0.09 \cdot 3 \mathrm{Pz}^{\mathrm{O} 2}$ & + \\
\hline $19 \cdot 3 \mathrm{Pz}^{O 3}$ & $+0.01 \cdot 2 \mathrm{Pz}^{\mathrm{F} 2}$ & $3 \mathrm{Pz}^{\mathrm{F} 2}$ & \\
\hline $02 \cdot 2 \mathrm{Px}{ }^{\mathrm{F} 1}$ & $0.02 \cdot 3 \mathrm{Px}^{\mathrm{F} 1}$ & $0.01 \cdot 3 \mathrm{Px}^{\mathrm{F} 4}$ & \\
\hline $\mathrm{z}^{\mathrm{F} 4}$ & $\mathrm{Pz}^{\mathrm{C} 2}$ & $\mathrm{Pz}^{\mathrm{C} 2}$ & \\
\hline $06 \cdot 4 \mathrm{Pz}^{\mathrm{C} 2}$ & $+0.22 \cdot 3 \mathrm{Pz}^{C 5}$ & $\mathrm{Px}^{\mathrm{C} 5}$ & \\
\hline $15 \cdot 5 \mathrm{Px} \mathrm{C}^{\mathrm{C}}$ & $2 \mathrm{Pz} 9$ & & \\
\hline $01 \cdot 4 \mathrm{~s}^{\mathrm{H} 9}$ & $-0.10 \cdot 2 \mathrm{Pz}^{\mathrm{C} 10}$ & $0.01 \cdot 3 \mathrm{sC}^{11}$ & \\
\hline \multicolumn{4}{|c|}{$0.01 \cdot 4 \mathrm{~s}^{\mathrm{C} 11}-0.01 \cdot 2 \mathrm{PzC}^{12}-0.02 \cdot 3 \mathrm{PzC}^{12}$} \\
\hline$\phi$ & $-0.09 \cdot 2 \mathrm{Pz}^{\mathrm{N}}$ & $1-0.13 \cdot \mathrm{Pz}^{\mathrm{N} 1}$ & \\
\hline 18 & $3 \mathrm{Px}^{\mathrm{N} 3}$ & +0 & \\
\hline $5 \mathrm{Pz}^{O 1}$ & $+\quad 0.0$ & $\mathrm{Pz}^{\mathrm{O} 2}$ & \\
\hline $10 \cdot 4 \mathrm{Pz}^{\mathrm{O} 2}$ & $+0.09 \cdot 2 \mathrm{Pz}^{\mathrm{O} 3}$ & $\mathrm{Py}^{\mathrm{F} 2}$ & \\
\hline $02 \cdot 3 \mathrm{Py}^{\mathrm{F} 2}$ & $0.03 \cdot 2 \mathrm{Pz}^{\mathrm{F} 1}$ & $\mathrm{Py}^{\mathrm{F} 1}$ & \\
\hline $04 \cdot 3 \mathrm{Pz}^{\mathrm{F} 1}$ & $0.01 \cdot 3 \mathrm{~s}^{\mathrm{F} 5}$ & $4 \mathrm{Px}^{\mathrm{F} 5}$ & \\
\hline $02 \cdot 2 \mathrm{Px}^{\mathrm{F} 4}$ & $+0.02 \cdot 3 \mathrm{Pz}^{\mathrm{F} 4}$ & $0.04 \cdot 4 \mathrm{Px}^{\mathrm{F} 4}$ & \\
\hline 0 & & & \\
\hline
\end{tabular}

\subsection{Electrical properties}

Dipole moment, polarizability and hyperpolarizabilities, which are important parameters in structural chemistry, have been a subject of intense investigations on molecules with large 
Table 3. Second-order perturbation theory analysis of Fock matrix in NBO basic corresponding to the intramolecular bonds of the title molecule.

\begin{tabular}{|c|c|c|c|c|c|c|c|c|c|c|c|}
\hline \multirow[t]{2}{*}{ Donor (i) } & \multicolumn{2}{|c|}{$\mathrm{ED}(\mathrm{I})(\mathrm{e})$} & \multirow[t]{2}{*}{ Acceptor $(\mathrm{j})$} & \multicolumn{2}{|c|}{$\mathrm{ED}(\mathrm{j})(\mathrm{e})$} & \multicolumn{6}{|c|}{$\mathrm{E}(2)^{\mathrm{a}}(\mathrm{kcal} / \mathrm{mol}) \mathrm{E}(\mathrm{j})-\mathrm{E}(\mathrm{i})^{\mathrm{b}}$ (a.u.) $\mathrm{F}(\mathrm{i}, \mathrm{j})^{\mathrm{c}}$ (a.u.) } \\
\hline & $\mathrm{HF}$ & B3LYP & & $\mathrm{HF}$ & B3LYP & $\mathrm{HF}$ & B3LYP & $\mathrm{HF}$ & B3LYP & $\mathrm{HF}$ & B3LYP \\
\hline$\sigma\left(\mathrm{N}_{1}-\mathrm{C}_{2}\right)$ & 1.9879 & 1.9878 & $\sigma^{*}\left(\mathrm{~N}_{1}-\mathrm{C}_{6}\right)$ & 0.0202 & 0.0241 & 2.30 & 1.31 & 1.97 & 1.38 & 0.060 & 0.038 \\
\hline$\sigma\left(\mathrm{N}_{1}-\mathrm{C}_{2}\right)$ & 1.9879 & 1.9878 & $\sigma^{*}\left(\mathrm{~N}_{3}-\mathrm{C}_{2}\right)$ & 0.0385 & 0.0453 & 2.58 & 1.83 & 1.99 & 1.40 & 0.064 & 0.046 \\
\hline$\sigma\left(\mathrm{N}_{1}-\mathrm{C}_{2}\right)$ & 1.9879 & 1.9878 & $\sigma^{*}\left(\mathrm{C}_{6}-\mathrm{C}_{9}\right)$ & 0.0173 & 0.0212 & 3.68 & 3.30 & 1.83 & 1.29 & 0.073 & 0.058 \\
\hline$\pi\left(\mathrm{N}_{1}-\mathrm{C}_{2}\right)$ & 1.7786 & 1.7579 & $\pi^{*}\left(\mathrm{~N}_{1}-\mathrm{C}_{2}\right)$ & 0.3615 & 0.4109 & 1.30 & 1.06 & 0.57 & 0.31 & 0.025 & 0.017 \\
\hline$\pi\left(\mathrm{N}_{1}-\mathrm{C}_{2}\right)$ & 1.7786 & 1.7579 & $\pi^{*}\left(\mathrm{~N}_{3}-\mathrm{C}_{4}\right)$ & 0.3804 & 0.4392 & 12.50 & 8.34 & 0.57 & 0.31 & 0.078 & 0.048 \\
\hline$\pi\left(\mathrm{N}_{1}-\mathrm{C}_{2}\right)$ & 1.7786 & 1.7579 & $\pi^{*}\left(\mathrm{C}_{5}-\mathrm{C}_{6}\right)$ & 0.2513 & 0.2910 & 53.52 & 25.47 & 0.62 & 0.35 & 0.164 & 0.086 \\
\hline$\sigma\left(\mathrm{C}_{4}-\mathrm{C}_{5}\right)$ & 1.9722 & 1.9704 & $\sigma^{*}\left(\mathrm{O}_{1}-\mathrm{C}_{10}\right)$ & 0.0104 & 0.0144 & 4.72 & 3.58 & 1.50 & 0.98 & 0.075 & 0.053 \\
\hline$\sigma\left(\mathrm{C}_{4}-\mathrm{C}_{5}\right)$ & 1.9722 & 1.9704 & $\sigma^{*}\left(\mathrm{C}_{5}-\mathrm{C}_{6}\right)$ & 0.0318 & 0.0370 & 4.11 & 2.80 & 1.82 & 1.29 & 0.077 & 0.054 \\
\hline$\pi\left(\mathrm{C}_{5}-\mathrm{C}_{6}\right)$ & 1.6883 & 1.6586 & $\sigma^{*}\left(\mathrm{C}_{7}-\mathrm{C}_{8}\right)$ & & & 4.69 & 50 & 0.98 & 0.64 & 0.065 & 0.046 \\
\hline$\sigma\left(\mathrm{C}_{5}-\mathrm{C}_{7}\right)$ & 1.9755 & 1.9715 & $\sigma^{*}\left(\mathrm{~N}_{1}-\mathrm{C}_{6}\right)$ & 0.0202 & 0.0241 & 4.09 & 3.47 & 1.63 & 1.14 & 0.073 & 0.056 \\
\hline $\mathrm{LP} 3\left(\mathrm{Cl}_{1}\right)$ & 1.9312 & 1.9091 & $\pi^{*}\left(\mathrm{~N}_{1}-\mathrm{C}_{2}\right)$ & 0.3615 & 0.4109 & 24.36 & 16.54 & 0.58 & 0.29 & 0.115 & 0.068 \\
\hline $\mathrm{LP} 1\left(\mathrm{~N}_{1}\right)$ & 1.9240 & 1.9038 & $\sigma^{*}\left(\mathrm{Cl}_{1}-\mathrm{C}_{2}\right)$ & 0.0508 & 0.0729 & 6.82 & 4.40 & 0.90 & 0.49 & 0.070 & 0.042 \\
\hline $\mathrm{LP} 1\left(\mathrm{~N}_{1}\right)$ & 1.9240 & 1.9038 & $\sigma^{*}\left(\mathrm{~N}_{3}-\mathrm{C}_{2}\right)$ & 0.0385 & 0.0453 & 17.38 & 13.42 & 1.35 & 0.87 & 0.138 & 0.098 \\
\hline $\operatorname{LP} 1\left(\mathrm{~N}_{1}\right)$ & 1.9240 & 1.9038 & $\sigma^{*}\left(\mathrm{C}_{5}-\mathrm{C}_{6}\right)$ & 0.0318 & 0.0370 & 11.53 & 21 & 1.40 & 0.92 & 0.115 & 0.083 \\
\hline $\mathrm{LP} 1\left(\mathrm{~N}_{3}\right)$ & 1.9139 & 1.8883 & $\sigma^{*}\left(\mathrm{Cl}_{1}-\mathrm{C}_{2}\right)$ & 0.0508 & 0.0729 & 5.86 & 3.75 & 0.91 & 0.50 & 0.066 & 0.039 \\
\hline $\mathrm{LP} 1\left(\mathrm{~N}_{3}\right)$ & 1.9139 & 1.8883 & $\sigma^{*}\left(\mathrm{~N}_{1}-\mathrm{C}_{2}\right)$ & 0.0350 & 0.0412 & 15.16 & 11.69 & 1.40 & 0.91 & 0.132 & 0.094 \\
\hline $\operatorname{LP1}\left(\mathrm{N}_{3}\right)$ & 1.9139 & 1.8883 & $\sigma^{*}\left(\mathrm{O}_{1}-\mathrm{C}_{4}\right)$ & 0.0355 & 0.0476 & 9.68 & 6.14 & 1.22 & 0.73 & 0.098 & 0.061 \\
\hline $\mathrm{LP} 1\left(\mathrm{O}_{1}\right)$ & 1.9667 & 1.9624 & $\sigma^{*}\left(\mathrm{~N}_{3}-\mathrm{C}_{4}\right)$ & 0.0250 & 0.0296 & 9.14 & 6.74 & 1.60 & 1.08 & 0.108 & 0.076 \\
\hline $\mathrm{LP} 2\left(\mathrm{O}_{1}\right)$ & 1.8539 & 1.8094 & $\sigma^{*}\left(\mathrm{~N}_{3}-\mathrm{C}_{4}\right)$ & 0.0250 & 0.0296 & 58.43 & 40.34 & 0.64 & 0.32 & 0.184 & 0.108 \\
\hline$\pi^{*}\left(\mathrm{~N}_{1}-\mathrm{C}_{2}\right)$ & 0.3615 & 0.4109 & $\pi^{*}\left(\mathrm{C}_{5}-\mathrm{C}_{6}\right)$ & 0.2513 & 0.2910 & 91.39 & 64.86 & 0.06 & 0.04 & 0.115 & 0.077 \\
\hline$\pi^{*}\left(\mathrm{~N}_{3}-\mathrm{C}_{4}\right)$ & 0.3804 & 0.4392 & $\pi^{*}\left(\mathrm{C}_{5}-\mathrm{C}_{6}\right)$ & 0.2513 & 0.2910 & 100.30 & 77.72 & 0.06 & 0.04 & 0.119 & 0.083 \\
\hline
\end{tabular}

$\mathrm{ED}=$ electron density.

${ }^{a} E(2)$ means energy of hyperconjugative interactions (stabilization energy).

${ }^{b}$ Energy difference between donor and acceptor $\mathrm{i}$ and $\mathrm{j}$ NBO orbitals.

${ }^{c} \mathrm{~F}(\mathrm{i}, \mathrm{j})$ is the Fock matrix element between $\mathrm{i}$ and $\mathrm{j}$ NBO orbitals.

Table 4. The calculated total molecular energies, frontier orbital energies, electronegativity, hardness and softness for the title molecule.

\begin{tabular}{|c|c|c|}
\hline & $\mathrm{HF} / 6-311++\mathrm{G}(\mathrm{d}, \mathrm{p})$ & B3LYP/6-311++G(d,p) \\
\hline $\mathrm{E}_{\text {HOMO }}(\mathrm{eV})$ & -9.6052 & -7.1036 \\
\hline $\mathrm{E}_{\text {LUMO }}(\mathrm{eV})$ & 0.9178 & -1.3464 \\
\hline$\Delta \mathrm{E}=\mathrm{E}_{\mathrm{LUMO}}-\mathrm{E}_{\mathrm{HOMO}}(\mathrm{eV})$ & 10.5230 & 5.7572 \\
\hline $\mathrm{I}(\mathrm{eV})$ & 9.6052 & 7.1036 \\
\hline $\mathrm{A}(\mathrm{eV})$ & -0.9178 & 1.3464 \\
\hline$\chi(\mathrm{eV})$ & 4.3437 & 4.2250 \\
\hline$\eta(\mathrm{eV})$ & 5.2615 & 2.8786 \\
\hline $\mathrm{S}\left(\mathrm{eV}^{-1}\right)$ & 0.0950 & 0.1737 \\
\hline $\mathrm{E}_{\text {TOTAL }}$ (a.u) & -1027.629 & -1031.814 \\
\hline
\end{tabular}




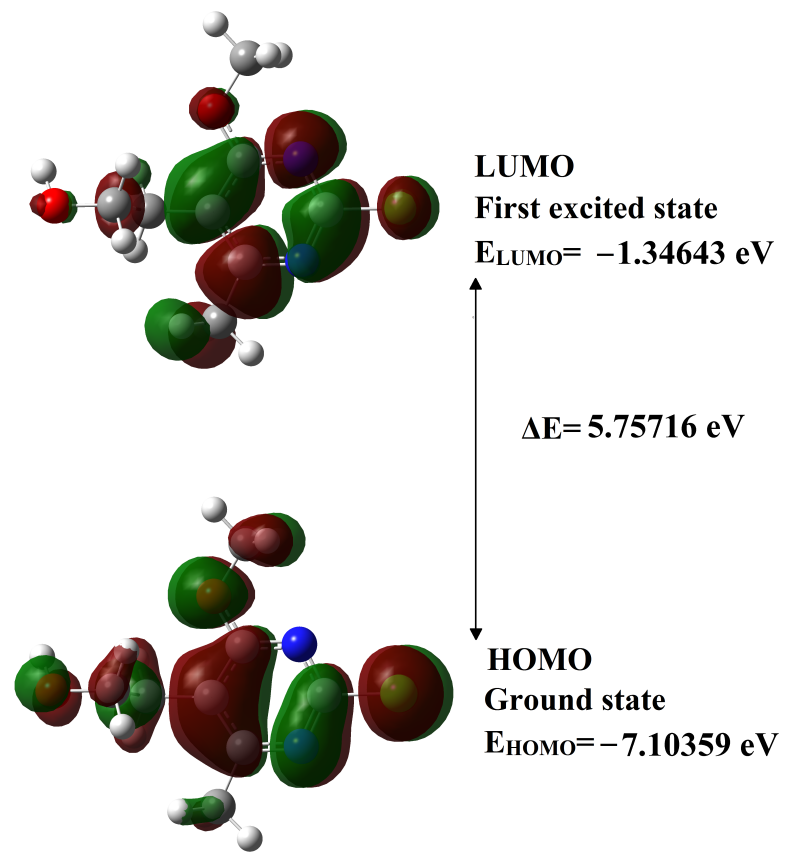

Fig. 7. 3D plots frontier orbital energies of the title molecule using B3LYP/6-311++G(d,p) level.

hyperpolarizabilities, since these substances have a potential as the constituents of nonlinear optical materials. The polarizabilities and hyperpolarizabilities characterize the response of a system in an applied electric field [45, 46]. Electric polarizability is a fundamental characteristics of atomic and molecular systems [47]. This parameter can determine not only the strength of molecular interactions (such as the long-range intermolecular induction, dispersion forces, etc.) and the cross sections of different scattering and collision processes, but also the nonlinear optical properties (NLO) of the system [48]. The theory of electric polarizability is a key element for the rational interpretation of a wide range of phenomena, from nonlinear optics [49] and electron scattering [50] to phenomena induced by intermolecular interactions [51].

In this paper, we present the values of the total static dipole moment $(\mu)$, the mean polarizability $(\langle\alpha\rangle)$, the anisotropy of the polarizability $(\Delta \alpha)$ and the mean first-order hyperpolarizability $(\langle\beta\rangle)$ as defined in the following equations [52]:

$$
\mu=\left(\mu_{x}^{2}+\mu_{y}^{2}+\mu_{z}^{2}\right)^{1 / 2}
$$

$$
\langle\alpha\rangle=\left(\frac{\alpha_{x x}+\alpha_{y y}+\alpha_{z z}}{3}\right)
$$

$\Delta \alpha=\left(\frac{\left(\alpha_{x x}-\alpha_{y y}\right)^{2}+\left(\alpha_{y y}-\alpha_{z z}\right)^{2}+\left(\alpha_{z z}-\alpha_{x x}\right)^{2}}{2}\right)^{\frac{1}{2}}$

$$
\langle\beta\rangle=\left(\beta_{x}^{2}+\beta_{y}^{2}+\beta_{z}^{2}\right)^{\frac{1}{2}}
$$

$$
\begin{aligned}
\beta_{x} & =\beta_{x x x}+\beta_{x y y}+\beta_{x z z} \\
\text { where } & \beta_{y}=\beta_{y y y}+\beta_{x x y}+\beta_{y z z} \\
\beta_{z} & =\beta_{z z z}+\beta_{x x z}+\beta_{y y z}
\end{aligned}
$$

The total static dipole moment, the mean polarizability $(\langle\alpha\rangle)$, the anisotropy of the polarizability $(\Delta \alpha)$ and the mean first-order hyperpolarizability $(\langle\beta\rangle)$ have been calculated for the title molecule using Hartree-Fock (HF) and density functional theory method (DFT/B3LYP) with the $6-311++\mathrm{G}(\mathrm{d}, \mathrm{p})$ basis set. The $\alpha$ and $\beta$ components of Gaussian 09W output are reported in atomic units and, therefore, the calculated values have been converted into electrostatic units $(\alpha$ : 1 a.u. $=0.1482 \times 10^{-24}$ esu. and $\beta: 1$ a.u. $=$ $8.6393 \times 10^{-33}$ esu.) and given in Table 5 . The direction of the dipole moment vector in a molecule depends on the centers of positive and negative charges. According to the present calculations in Table 5, dipole moment for the title molecule has been calculated as 1.3036 Debye for HF level and 1.3269 Debye for B3LYP level. The anisotropy of polarizability, polarizability and the first-order hyperpolarizability have been calculated as $19.6158 \times 10^{-24}, 10.6885 \times 10^{-24}$ and $1499.4672 \times 10^{-33} \mathrm{esu}$, respectively, at B3LYP/6$311++\mathrm{G}(\mathrm{d}, \mathrm{p})$ level for the title molecule (Table 5). Additionally, it has been noticed that hyperpolarizability in xyy direction is higher due to the delocalization of the charge cloud. The maximum $\beta$ value is due to intermolecular hydrogen bonds and $\pi-\pi$ stacking interactions. The obtained maximum $\beta$ value indicates that the displacement of the charge cloud is larger in that particular direction. Obtained hyperpolarizability values show that the title molecule exhibits considerable NLO character as compared to previously calculated molecules [53-55]. 
Table 5. Longitudinal component of the total static dipole moment ( $\mu$, in Debye), the mean polarizability ( $\langle\alpha\rangle$, in $\left.10^{-24} \mathrm{esu}\right)$, the anisotropy of the polarizability $\left(\Delta \alpha\right.$, in $10^{-24}$ esu) and the mean first hyperpolarizability $\left(\langle\beta\rangle\right.$, in $\left.10^{-33} \mathrm{esu}\right)$ for the title molecule.

\begin{tabular}{ccc}
\hline Parameters & HF/6-311++G(d,p) & B3LYP/6-311++G(d,p) \\
\hline \hline$\mu$ & 1.3036 & 1.3269 \\
$\langle\alpha\rangle$ & 17.3578 & 19.6158 \\
$\Delta \alpha$ & 8.6026 & 10.6885 \\
$\langle\beta\rangle$ & 1035.7791 & 1499.4672
\end{tabular}

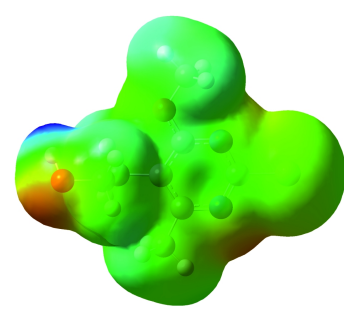

(a)

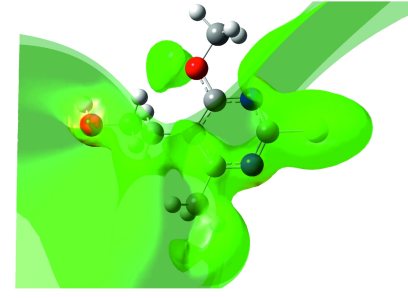

(b)
Fig. 8. Molecular electrostatic potential (MEP) (a) and electrostatic surface potential (ESP) (b) for the title molecule using B3LYP/6-311++G(d,p).

\subsection{Molecular surfaces}

The molecular electrostatic potential (MEP) surface, which is a method of mapping electrostatic potential onto the iso-electron density surface, simultaneously displays electrostatic potential (electron + nuclei) distribution, molecular shape, size and dipole moments of a molecule and it provides a visual method to understand the relative polarity [56]. The molecular electrostatic potential (MEP) has been established as a useful quantity to explain hydrogen bonding and structure activity of molecular behaviors. The color scheme for the MEP surface is red (electron-rich or partially negative charge), blue (electron-deficient or partially positive charge), light blue (slightly electrondeficient region), yellow (slightly electron-rich region), respectively. Areas of low potential, red, are characterized by an abundance of electrons. Areas of high potential, blue, are characterized by a relative absence of electrons.

To predict reactive sites for electrophilic and nucleophilic attack for the title molecule, the
3D plot of MEP simulated at the B3LYP/6$311++\mathrm{G}(\mathrm{d})$ level is given in Fig. 8. From Fig. 8, the most negative region is located over hydroxyl $\mathrm{O}$ atom as well as the $\mathrm{N}$ atoms and $\mathrm{Cl}$ atom, while the most positive regions are located over hydroxyl $\mathrm{H}$ atom and methyl $\mathrm{H}$ atoms. Additionally, the contour map of molecular electrostatic potential surface was discussed and the polarization effect is clearly visible in Fig. 8.

\subsection{Mulliken and natural (NBO) charge analysis}

Atomic charges play an important role in quantum chemistry and a lot of research works continue to refine the concept of an atomic charge. It is clear that Mulliken populations yield one of the simplest pictures of charge distribution and Mulliken charges render net atomic populations in the molecule [57]. The charge distribution in the title molecule has been calculated by the Mulliken and NBO methods at $\mathrm{HF} / 6-311++\mathrm{G}(\mathrm{d}, \mathrm{p})$ and B3LYP/6-311++G(d,p) levels of theory. The obtained results are given in Fig. 9. As can be seen, the magnitudes of the carbon Mulliken charges, found to be either positive or negative, change from -0.425047 to 0.574649 for the title molecule. The Mulliken charges show a behavior similar to that of the NBO charges. The all protons have a positive charge, while the oxygen atoms have negative charges.

\section{Conclusions}

The detailed investigation on 2-chloro-5-(2hydroxyethyl)-4-methoxy-6-methylpyrimidine has 

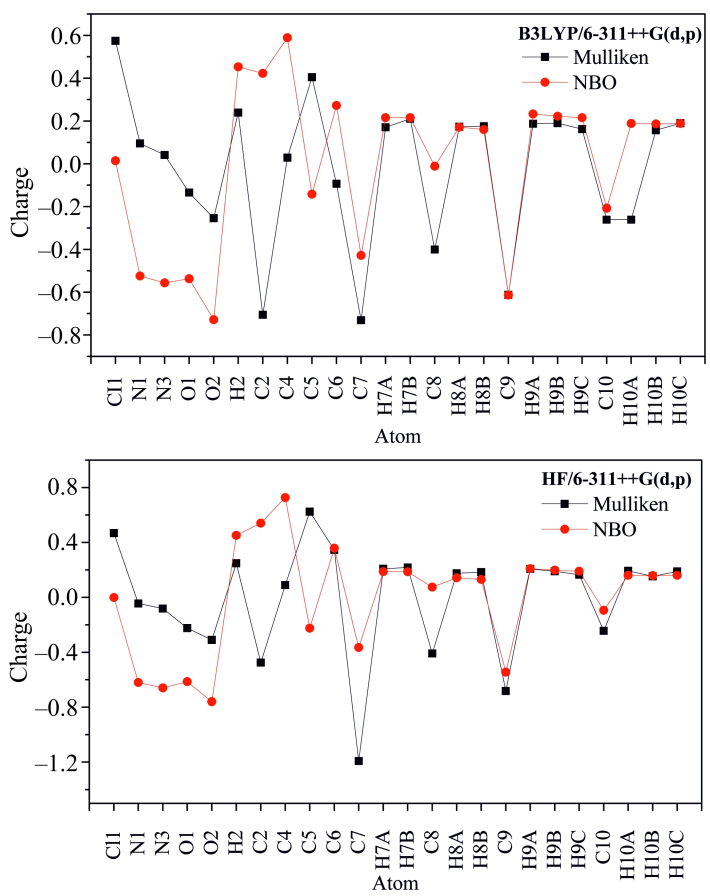

Fig. 9. Comparison of Mulliken and NBO charges for the title molecule.

been performed using quantum chemical calculations. Based on the optimized structures, ${ }^{1} \mathrm{H}$ and ${ }^{13} \mathrm{C}$ NMR spectra were simulated, and the obtained results were compared with the experimental ones. The obtained geometric parameters, ${ }^{1} \mathrm{H}$ and ${ }^{13} \mathrm{C}$ NMR chemical shifts results seem to be in a good agreement with the experimental data.

- Conformational analysis was performed, and the most stable conformers of the title molecule were obtained based on the PES scan method. The potential energy surface was built by varying the C6-C5-C7$\mathrm{C} 8$ dihedral angle, and the obtained stationary points were confirmed. The energy scan results revealed that the value of the dihedral angle leading to a minimum energy is $255.674^{\circ}$.

- NLO investigations of the title molecule, which has pyrimidine ring and 2hydroxyethyl chain substituted by various electron donating/withdrawing atoms/groups, have been performed. According to obtained NLO results, the title molecule exhibits considerable NLO character. Also, the strong hyperconjugative interactions with the large interaction energies demonstrate that the intramolecular charge transfer occurs in the title molecule.

- The relative stabilities, HOMO-LUMO energy gaps and implications of the electronic properties were examined and discussed. Additionally, the ionization potential (I), the electron affinity (A), the absolute electronegativity $(\chi)$, the absolute hardness $(\eta)$ and softness (S) parameters were obtained from HOMO-LUMO energies for the title molecule.

- The ESP and MEP plots for the title molecule demonstrated the distribution of atomic charges among atoms, both nucleophilic and electrophilic, with respect to the difference between positive and negative charges. To sum up, the negative region (red) is mainly over the $\mathrm{N}$ and $\mathrm{O}$ atomic sites, which is caused by the contribution of lone-pair electrons of nitrogen and oxygen atoms, while the positive (blue) potential sites are around the hydrogen atoms. The title molecule exhibits strong intramolecular charge transfer and shows the second-order nonlinearity.

\section{References}

[1] Kraljevic T.G., Krištafor S., Šuman L., Bioorgan. Med. Chem., 18 (2010), 2704.

[2] PIR H., GÜnay N., TAMer Ö., Spectrochim. Acta A, 112 (2013), 331.

[3] Das P., Spears C.P., Shahinian A.H., Bioorgan. Med. Chem. Lett., 6 (1996), 2477.

[4] Baba M., De Clercq E., TanaKa H., Mol. Pharmacol., 39 (1991), 805.

[5] Balzarini J., Karlsson A., De Clerce E., Mol. Pharmacol., 44 (1993), 694.

[6] Mai A., Artico M., Sbardella G., J. Med. Chem., 40 (1997), 1447.

[7] Prekupec S., Makuc D., Plavec J., Antivir. Chem. Chemother., 16 (2005), 327.

[8] Prekupec S., Makuc D., Plavec J., J. Med. Chem., 50 (2007), 3037.

[9] Heidelberger C., Pyrimidine and Pyrimidine Antimetabolites, in: Holland J.F., FreI E. (Eds.), Cancer Medicine, Lea and Febiger, Philadelphia, 1984. 
[10] Sigmond J., Peters G.J., Nucleos. Nucleot. Nucl., 24 (2005), 1997.

[11] DE ClercQ E., WAlker R.T., Pharmacol. Therapeut., 26 (1984), 1.

[12] De Clercq E., Descamps J., De Somer P., P. Natl. Acad. Sci. USA, 76 (1979), 2947.

[13] Chu C.K., Schinazi R.F., Ahn M.K., J. Med. Chem., 32 (1989), 612.

[14] Griengl H., Bodenteich M., Hayden W., J. Med. Chem., 28 (1985), 1679.

[15] DE ClercQ E., Balzarini J., Descamps J., Biochem. Pharmacol., 30 (1981), 495.

[16] Barr P.J., Robins M.J., SANTi D.V., BiochemistryUS, 22 (1983), 1696.

[17] Prober J.M., Trainer G.L., Dam R.J., Science, 238 (1987), 336

[18] Povsic T.J., Dervan P.B., J. Am. Chem. Soc., 112 (1990), 9428.

[19] Avci D., Atalay Y., Int. J. Quantum Chem., 109 (2009), 328.

[20] PIR H., Gunay N., TAmer Ö., Mater. Sci.-Poland, 31 (2013), 357.

[21] Pir H., Gunay N., Avci D., Spectrochim. Acta A, 96 (2012), 916

[22] Avci D., Basoglu A., Atalay Y., Int. J. Quantum Chem., 111 (2011), 130.

[23] BaşoĞlu A., Avci D., Atalay Y., Spectrochim. Acta A, 79 (2011), 1425.

[24] Avci D., Atalay Y., Struct. Chem., 20 (2009), 185.

[25] Dinçer M., Avci D., ŞEKerci M., J. Mol. Model., 14 (2008), 823.

[26] Avci D., Spectrochim. Acta A, 82 (2011), 37.

[27] Pir H., Gunay N., Avci D., Indian J. Phys., 86 (2012), 1049.

[28] Becke A.D., J. Chem. Phys., 98 (1993), 5648.

[29] Lee C., Yang W., PArr R.G., Phys. Rev. B, 37 (1988), 785.

[30] Frisch M. J., Trucks G. W., Schlegel H. B., Gaussian 09, Gaussian Inc., Wallingford CT, 2009.

[31] Dennington R., Keith T., Millam J., GaussView, 2009.

[32] Ditchfield R., Mol. Phys., 27 (1974), 789.

[33] Rohling C.M., Allen L.C., Ditchfield R., Chem. Phys., 87 (1984), 9.

[34] Avci D., Atalay Y., Int. J. Quantum Chem., 109 (2009), 328.

[35] Keith T.A., Bader R.F.W., Chem. Phys. Lett., 94 (1992), 1.
[36] Keith T.A., Bader R.F.W., Chem. Phys. Lett., 210 (1993), 223

[37] Atalay Y., Avci D., Basoglu A., Spectrochim. Acta A, 71 (2008), 760.

[38] Del Giudice M.R., Settimu G., Delfini M., Tetrahedron, 40 (1984), 4067.

[39] Weinhold F., LAndis C., Valency and Bonding: A Natural Bond Orbital Donor-Acceptor Perspective. Cambridge University Press, Cambridge, 2005.

[40] Reed A.E., Curtiss L.A., Weinhold F., Chem. Rev., 88 (1988), 899.

[41] Reed A.E., Weinstock R.B., Weinhold F., $J$. Chem. Phys., 83 (1985), 735.

[42] Chocholousova J., Spirko V.V., Hobza P., Phys. Chem. Chem. Phys., 6 (2000), 37.

[43] Fukui K., Science, 218 (1982), 747.

[44] Pearson R.G., P. Natl. Acad. Sci. USA, 83 (1986), 8440.

[45] Zhang C.R., Chem H.S., Wang G.H., Chem. Res. Chinese U., 20 (2004), 640.

[46] Kumar P.S., Vasudevan K., Prakasam A., Spectrochim. Acta A, 77 (2010), 45.

[47] Buckingham A.D., Adv. Chem. Phys., 12 (1967), 107.

[48] Christiansen O., Gauss J., Stanton J.F., Chem. Phys. Lett., 305 (1999), 147.

[49] Bloembergen N., Nonlinear optics, Benjamin, New York, 1965.

[50] Lane N.F., Rev. Mod. Phys., 52 (1980), 29.

[51] BIRnbaum G. (Ed.), Phenomena Induced by Intermolecular Interactions, Plenum, New York, 1980.

[52] Maroulis G., J. Chem. Phys., 113 (2000), 1813.

[53] Avci D., BaşoĞLU A., Atalay Y., Int. J. Quantum Chem., 111 (2011), 130.

[54] Öner N., Tamer Ö., Avci D., Atalay Y., Spectrochim. Acta A, 133 (2014), 542.

[55] Tamer Ö, Dege N., Demirtaş G., Avci D., AtaLAY Y., Macit M., ŞAHIN S., J. Mol. Struct., 1063 (2014), 295.

[56] Fleming I., Frontier Orbitals and Organic Chemical Reactions, John Wiley and Sons, New York, 1976.

[57] Mulliken R.S., J. Chem. Phys., 23 (1955), 1833.

[58] Mukherjee V., Singh N.P., YAdaV R.A., Spectrochim. Acta A, 73 (2009), 249. 